\title{
FITORREMEDIAÇÃO DE SOLO CONTAMINADO COM O HERBICIDA PICLORAM POR PLANTAS DE Panicum maximum EM FUNÇÃO DO TEOR DE ÁGUA NO SOLO
}

\author{
RENATO L. DE ASSIS ${ }^{1}$, SERGIO DE O. PROCÓPIO ${ }^{2}$, MARCOS L. DO CARMO ${ }^{3}$, \\ FÁBIO R. PIRES ${ }^{4}$, ALBERTO CARGNELUTTI FILHO ${ }^{5}$, GUILHERME B. P. BRAZ $^{6}$ \\ WELLINGTON F. P. SILVA ${ }^{7}$
}

\begin{abstract}
RESUMO: O objetivo deste trabalho foi avaliar a influência de lâminas de água no solo sobre a fitorremediação de solo contaminado com o herbicida picloram por plantas de Panicum maximum cv Tanzânia. O experimento foi conduzido em casa de vegetação, e os tratamentos, em número de 12, foram compostos pela combinação entre quatro níveis diários de reposição da água, através das lâminas de água evaporada $(80 ; 90 ; 100$ e 110\% da quantidade de água evaporada) e de três doses do picloram $\left(0 ; 80 \mathrm{e} 160 \mathrm{~g} \mathrm{ha}^{-1}\right)$. A quantidade de água evaporada foi determinada por meio de dois evaporímetros. Após a aplicação do herbicida, foi realizada a semeadura da espécie vegetal fitorremediadora. Noventa dias após a emergência, as plantas de capim-tanzânia foram dessecadas, e a parte aérea, descartada. Terminada esta etapa, efetuou-se a semeadura da soja como bioindicadora da presença do picloram, determinando-se fitotoxicidade, altura e massa verde e seca. A soja mostrou-se extremamente sensível à presença do picloram no solo. Constatou-se que os valores extremos de umidade avaliados, 80 e $110 \%$ da reposição diária da lâmina de água evaporada, favoreceram a remediação de solos contaminados com o herbicida picloram. A otimização da fitorremediação não é significativa quando se avaliou o resíduo correspondente a $160 \mathrm{~g} \mathrm{ha}^{-1}$ do herbicida.
\end{abstract}

PALAVRAS-CHAVE: residual de herbicidas, mimetizadores de auxinas, soja, evaporação de água.

\section{PHYTOREMEDIATION OF SOIL CONTAMINATED BY PICLORAM IN Panicum maximum UNDER DIFFERENT WATER CONTENT ON THE SOIL}

\begin{abstract}
The objective of this work was to evaluate the influence of water layers on phytoremediation of soil contaminated by picloram herbicide in Tanzania grass (Panicum maximum cv Tanzânia). The experiment was carried out in a greenhouse and groups of 12 treatments were made up of a combination of four daily levels of water replacement, by means of evaporated water layers $\left(80 ; 90 ; 100\right.$ and $110 \%$ of water evaporated) and three picloram levels $\left(0 ; 80\right.$ and $\left.160 \mathrm{~g} \mathrm{ha}^{-1}\right)$. The amount of water evaporated was determined using two evaporimeters. After the herbicide had been applied, the phytoremediating plant species was planted. Ninety days after emergence, the Tanzania grass was dried and the aerial part was discarded. When this step had finished, soybean was planted as a bioindicator for picloram presence, and phytotoxicity, height, green and dry mass were determined. Soybean was very sensitive to picloram in the soil. It was noted that the extreme humidity levels evaluated, 80 and $110 \%$ of the daily replacement of the evaporated water layers, were favorable to remediation of soils contaminated with picloram herbicide. Optimization of phytoremediation is not significant when a residue corresponding to $160 \mathrm{~g} \mathrm{ha}^{-1}$ of the herbicide was evaluated.
\end{abstract}

KEYWORDS: carryover, auxin agonists, soybean, water evaporation.

\footnotetext{
${ }^{1}$ Professor do Instituto Federal Goiano, Câmpus Iporá - GO, relassis@bol.com.br

${ }^{2}$ Embrapa Tabuleiros Costeiros, Aracaju - SE, Fone: (0XX79) 4009.1318, procopio@ cpatc.embrapa.br

${ }^{3}$ Professor da Faculdade de Agronomia/FESURV, Rio Verde - GO, Fone: (0XX64) 3620.2213, marcoslima@ fesurv.br

${ }^{4}$ Professor do CEUNES/UFES, São Mateus - ES, Fone: (OXX27) 3763.8650, fabiopires@ ceunes.ufes

${ }^{5}$ Professor do Centro de Ciências Rurais, Universidade Federal de Santa Maria - RS, cargnelutti@ pq.cnpq.br

${ }^{6}$ Mestrando em Agronomia, Universidade Estadual de Maringá, guilhermebrag@ gmail.com

${ }^{7}$ Eng ${ }^{0}$ Agrônomo, FESURV, Rio Verde - GO.

Recebido pelo Conselho Editorial em: 28-4-2008
}

Aprovado pelo Conselho Editorial em: 22-6-2010 


\section{INTRODUÇÃO}

Alguns herbicidas apresentam sintomas visuais imediatos de fitointoxicação após aplicação (CONSTANTIN et al., 2007a, b) ou com seus resíduos, quando plantas sensíveis são cultivadas em rotação. Dentre esses herbicidas, encontra-se o picloram, registrado no País, que vem sendo amplamente utilizado em pastagens (RODRIGUES \& ALMEIDA, 2005). O período de espera para o plantio de culturas sensíveis, recomendado pelo fabricante, é de cerca de três anos, a contar de sua aplicação. Esse fato pode limitar sua utilização em áreas onde o agricultor queira realizar sistemas de integração lavoura - pecuária.

$\mathrm{Na}$ busca de alternativas para minimizar esse problema, tem-se difundido o uso de plantas tolerantes para a remoção de determinados produtos. Essa técnica é conhecida como fitorremediação, e seu emprego tem sido indicado em áreas contaminadas com substâncias orgânicas e inorgânicas (CUNNINGHAM et al., 1996; PROCÓPIO et al., 2007; D’ANTONINO et al., 2009).

A fitorremediação baseia-se na tolerância que algumas espécies exibem a determinados produtos. No caso de compostos orgânicos, a tolerância pode ser resultante de processos, como a absorção e a translocação diferencial pela planta; a degradação parcial ou completa; e a transformação em compostos menos tóxicos, combinados e/ou ligados nos tecidos das plantas (ACCIOLY \& SIQUEIRA, 2000; SCRAMIN et al., 2001). Em geral, a maioria dos compostos orgânicos passa por alguma transformação nas células das plantas antes de serem isolados em vacúolos ou ligarem-se a estruturas celulares insolúveis, como a lignina (MACEK et al., 2000).

A fitorremediação também pode dar-se pela liberação de exsudatos radiculares, que estimulam a atividade microbiana, degradando o composto no solo e caracterizando, em algumas plantas, a aptidão rizosférica para a biorremediação de compostos tóxicos (CUNNINGHAM et al., 1996). Essa forma de fitorremediação é chamada de fitoestimulação.

Apesar da limitação que existe para fitorremediar herbicidas, por estes serem, muitas vezes, tóxicos às plantas, recentes pesquisas têm relatado a utilização de plantas na biodecomposição de pesticidas. Os herbicidas para os quais se têm observado resultados positivos quanto à fitorremediação, são principalmente atrazine e metolachlor (ANDERSON et al., 1994; ANDERSON \& COATS, 1995; PERKOVICH et al., 1996; RICE et al., 1997), e a espécie mais promissora tem sido Kochia scoparia. Estudos envolvendo solo rizosférico desta espécie evidenciaram que a degradação de metolachlor e, principalmente, de atrazine, foi maior quando comparada à de solos não vegetados. Estudos com trifluralin (ANDERSON et al., 1994), simazine (WILSON et al., 1999, 2000) e 2,4,5-T (BOYLE \& SCHANN, 1998) também têm sido relatados.

No Brasil, SCRAMIN et al. (2001) identificaram plantas daninhas, supostamente tolerantes aos herbicidas mais comumente utilizados nas áreas de cana-de-açúcar do Estado de São Paulo. Assim, para a utilização da fitorremediação como alternativa para descontaminação de solos e, no caso do picloram, para minimizar sua toxicidade em espécies sensíveis cultivadas em rotação, torna-se necessária a seleção de plantas que sejam capazes de degradá-lo/imobilizá-lo no solo ou na planta, principalmente se esta característica estiver também associada a outros benefícios ao solo, como é o caso dos adubos verdes.

O objetivo deste trabalho foi avaliar a influência de diferentes lâminas de água no solo contaminado com o herbicida picloram durante o processo de remediação por plantas de Panicum maximum (cultivar Tanzânia).

\section{MATERIAL E MÉTODOS}

O experimento foi conduzido em casa de vegetação da Fesurv - Universidade de Rio Verde, localizada no município de Rio Verde - GO, cujas coordenadas geográficas são: latitude de $17^{\circ} 47^{\prime} 24$ " S e longitude de 5056'31" W, e altitude de $698 \mathrm{~m}$. O período de condução do experimento foi de outubro de 2006 a março de 2007. 
Foram utilizadas amostras de solo classificado como Latossolo Vermelho distroférrico como substrato para o crescimento das plantas que, após secagem ao ar, foram passadas em peneira com 2 mm de malha e submetidas à caracterização química e textural (Tabela 1), conforme metodologia proposta pela EMBRAPA (1997). O teor de água na capacidade de campo foi determinado também segundo método da EMBRAPA (1997).

TABELA 1. Caracterização química e análise textural do Latossolo Vermelho distroférrico. Chemical characterization and texture analyses of a Dystroferric Red Latosol.

\begin{tabular}{cccccccccccccc}
\hline $\mathrm{pH}$ & $\mathrm{P}$ & $\mathrm{H}+\mathrm{Al}$ & $\mathrm{Al}$ & $\mathrm{K}$ & $\mathrm{Ca}$ & $\mathrm{Mg}$ & $\mathrm{CTC}$ & $\mathrm{V}$ & $\mathrm{M} . \mathrm{O}$ & Areia & Silte & Argila & C.C. \\
\cline { 2 - 12 }$\left(\mathrm{CaCl}_{2}\right)$ & $\mathrm{mg} \mathrm{dm}^{-3}$ & - & $-1,9$ & \\
4,1 & 0,3 & 2,9 & 0,05 & 0,04 & 0,06 & 0,21 & 3,26 & 9,88 & 12,79 & 290 & 150 & 560 & 201 \\
\hline
\end{tabular}

* Teor de água na capacidade de campo a -0,006 MPa.

Os tratamentos comparados foram: quatro níveis diários de reposição da água, através das lâminas de água evaporada (80; 90; 100 e 110\% da quantidade de água evaporada) e três doses do picloram ( $0 ; 80$ e $\left.160 \mathrm{~g} \mathrm{ha}^{-1}\right)$, totalizando 12 tratamentos. A quantidade de água evaporada média foi determinada empregando-se dois evaporímetros (recipientes instalados dentro da área experimental com área de borda de mesma dimensão dos vasos utilizados para plantio das espécies). Utilizou-se o delineamento experimental inteiramente casualizado, em esquema fatorial 4 x 3 , com quatro repetições.

Antes do preenchimento dos vasos com capacidade para $8 \mathrm{dm}^{3}$, o solo foi corrigido com calcário filler, utilizando-se do equivalente a $2 \mathrm{t} \mathrm{ha}^{-1}$, e adubado com o equivalente a $500 \mathrm{~kg} \mathrm{ha}^{-1} \mathrm{da}$ fórmula 08-20-18.

Após o preenchimento e umedecimento dos vasos, procedeu-se à aplicação do herbicida picloram, utilizando-se de um pulverizador costal pressurizado com $\mathrm{CO}_{2}$, acoplado de barra contendo duas pontas de pulverização TT 110.02, aplicando volume de calda equivalente a $200 \mathrm{~L} \mathrm{ha}^{-1}$. Após 48 horas da aplicação do herbicida, foi realizada a semeadura da espécie vegetal fitorremediadora Panicum maximum cv Tanzânia.

Dez dias após a emergência das plantas, realizou-se um desbaste, deixando-se dez plantas por vaso. Uma vez ao dia, todos os vasos recebiam reposição de água, considerando a quantidade de água evaporada. A quantidade de água reposta por tratamento levou em consideração a quantidade evaporada no evaporímetro, além de considerar as lâminas $(80 ; 90 ; 100$ e $110 \%)$, e, em todas as lâminas, o coeficiente de cultura de 0,9 (coeficiente para estágios iniciais de crescimento) e 1,0 (quando a cultura já apresentava crescimento ativo).

Monitoraram-se as temperaturas médias mensais, medidas na Estação Meteorológica da Universidade de Rio Verde, durante o período de condução do experimento, entre outubro de 2006 e março de 2007, as quais foram de 23,6; 23,3; 23,6; 23,5; 23,5 e $24,0{ }^{\circ} \mathrm{C}$, respectivamente.

Ao término do tempo estabelecido de atuação da espécie vegetal (90 dias após a emergência), estas foram dessecadas com glyphosate (1.800 $\mathrm{g} \mathrm{ha}^{-1}$ de equivalente ácido). Cinco dias após essa dessecação, as plantas foram cortadas na altura do coleto, sendo a parte aérea descartada. A seguir, foram retiradas amostras de solo de todos os vasos, sendo estas analisadas quimicamente. Após a análise dos resultados e tendo como base as necessidades da cultura da soja, procedeu-se a uma adubação de plantio específica para cada tratamento, a fim de se uniformizar a disponibilidade de nutrientes em cada unidade experimental. Terminada esta etapa, efetuou-se a semeadura da espécie bioindicadora da presença do picloram, soja (cultivar Monsoy 6101), distribuindo-se 10 sementes por vaso. Após a emergência das plantas de soja, procedeu-se a um desbaste, deixando-se três plantas por vaso. A irrigação foi uniformizada em todos os tratamentos, após o plantio da soja, sendo que, duas vezes ao dia, todos os vasos recebiam a mesma lâmina de irrigação.

Aos 15 e 40 dias após a emergência (DAE) da espécie bioindicadora avaliou-se a fitointoxicação de forma visual, utilizando-se de escala percentual, onde 0 (zero) significa ausência 
de sintomas, e $100 \%$ morte de todas as plantas. A altura média de plantas foi medida com régua, tendo como referência o meristema apical. Aos 40 DAE, as partes aéreas das plantas de soja foram cortadas rente ao solo, sendo o material vegetal imediatamente pesado em balança analítica para a determinação da massa verde da parte aérea. Após essa pesagem, esses materiais foram colocados em estufa com circulação forçada de ar à temperatura de $70 \pm 2{ }^{\circ} \mathrm{C}$, por 72 horas. Ao final da secagem, o material foi pesado para a determinação da massa seca da parte aérea.

Após a coleta e a tabulação dos dados, estes foram submetidos à análise de variância. A análise dos efeitos significativos dos níveis diários de reposição da umidade do solo, dentro de cada dose do herbicida, foi realizada por análise de regressão, sendo os coeficientes das equações testados pelo teste t a 5\% de significância, e os efeitos significativos das doses do picloram, em cada nível diário de reposição da umidade do solo, por meio do teste de Tukey, a 5\% de significância, devido ao número insuficiente de níveis para a confecção das equações de regressão.

\section{RESULTADOS E DISCUSSÃO}

Os resíduos do herbicida picloram no solo ocasionaram elevada intoxicação às plantas de soja cultivadas após a atuação das plantas de capim-tanzânia, independentemente da lâmina de reposição da água evaporada no solo (Tabela 2 e Figura 1). Esses resultados mostram a alta sensibilidade das plantas de soja à presença do picloram e reforça o cuidado com a semeadura dessa cultura em áreas com histórico de aplicações desse herbicida. Segundo WAX et al. (1969), a cultura da soja apresenta sensibilidade a quantidades extremamente baixas do herbicida picloram no solo.

O aumento na contaminação inicial do picloram (160 $\left.\mathrm{g} \mathrm{ha}^{-1}\right)$ acarretou maior intoxicação das plantas de soja aos 15 dias após a emergência da cultura (DAE), quando a reposição da lâmina de água evaporada no solo, durante a permanência das plantas de capim-tanzânia, foi de 80 e $110 \%$, mantendo esse comportamento na avaliação seguinte (40 DAE) (Tabela 2). Quando o nível inicial de contaminação do picloram foi de $160 \mathrm{~g} \mathrm{ha}^{-1}$, a reposição da água evaporada do solo praticamente não afetou a eficácia da fitorremediação, utilizando-se de plantas de capim-tanzânia (Figura 1).

TABELA 2. Intoxicação em plantas de soja semeadas após o cultivo prévio de Panicum maximum (cultivar Tanzânia), sob diferentes lâminas de água no solo contaminado previamente com o herbicida picloram. Intoxication in soybean plants planted after previous cultivation of Panicum maximum (Tanzania grass) under different water layers in soil previously contaminated with picloram herbicide.

\begin{tabular}{|c|c|c|c|c|}
\hline \multirow{3}{*}{$\begin{array}{l}\text { Doses de picloram } \\
\qquad\left(\mathrm{g} \mathrm{ha}^{-1}\right)\end{array}$} & \multicolumn{4}{|c|}{ Reposição Diária da Lâmina de Água Evaporada (\%) } \\
\hline & 80 & 90 & 100 & 110 \\
\hline & \multicolumn{4}{|c|}{ Intoxicação (\%) em Plantas de Soja aos 15 DAE* } \\
\hline 0 & $0,00 \mathrm{c}$ & $0,00 \mathrm{~b}$ & $0,00 \mathrm{~b}$ & $0,00 \mathrm{c}$ \\
\hline 80 & $60,00 \mathrm{~b}$ & $78,25 \mathrm{a}$ & $76,25 \mathrm{a}$ & $51,75 \mathrm{~b}$ \\
\hline 160 & $88,75 \mathrm{a}$ & $92,75 \mathrm{a}$ & $90,25 \mathrm{a}$ & $90,00 \mathrm{a}$ \\
\hline \multicolumn{5}{|c|}{ Intoxicação (\%) em Plantas de Soja aos 40 DAE } \\
\hline 0 & $0,00 \mathrm{c}$ & $0,00 \mathrm{~b}$ & $0,00 \mathrm{~b}$ & $0,00 \mathrm{c}$ \\
\hline 80 & $56,25 \mathrm{~b}$ & $77,00 \mathrm{a}$ & $79,50 \mathrm{a}$ & $54,50 \mathrm{~b}$ \\
\hline 160 & $90,50 \mathrm{a}$ & $89,00 \mathrm{a}$ & $91,25 \mathrm{a}$ & $91,75 \mathrm{a}$ \\
\hline
\end{tabular}

Médias não seguidas de mesma letra na vertical diferem pelo teste de Tukey, a 5\% de probabilidade. *DAE = dias após a emergência. 
$15 \mathrm{DAE}$

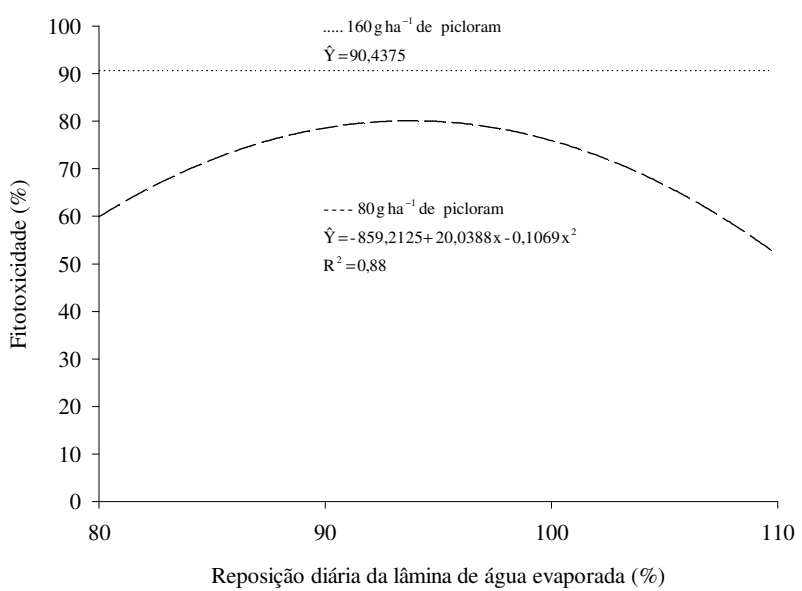

$40 \mathrm{DAE}$

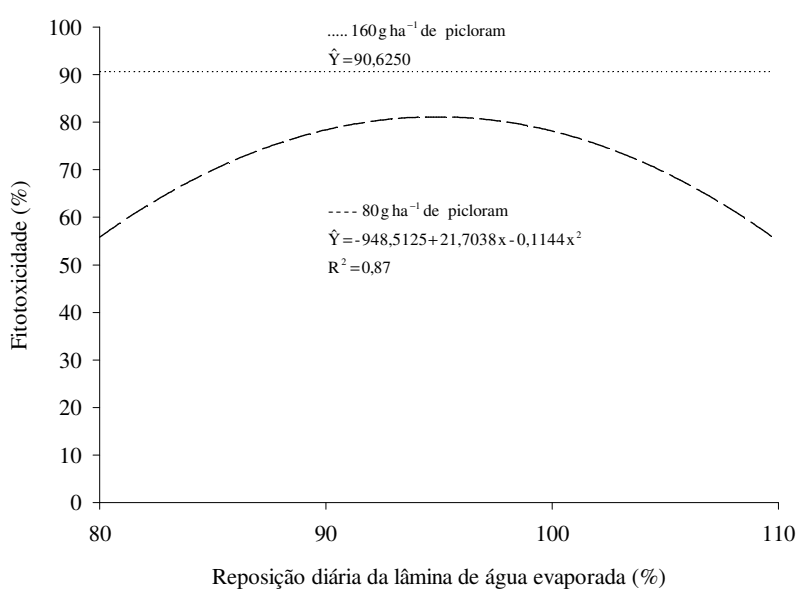

FIGURA 1. Intoxicação em plantas de soja aos 15 e 40 dias após a emergência, semeadas após o cultivo prévio de Panicum maximum (cultivar Tanzânia), sob diferentes lâminas de água no solo contaminado previamente com o herbicida picloram. Intoxication in soybean plants 15 to 40 days after emergence, planted after previously cultivation with Panicum maximum (Tanzania grass), under different water layers in soil contaminated with picloram herbicide.

No entanto, quando a contaminação inicial com o herbicida ocorreu em menor proporção $\left(80 \mathrm{~g} \mathrm{ha}^{-1}\right)$, a menor ou a maior reposição da água evaporada favoreceu a fitorremediação, chegando a reduzir os sintomas de intoxicação nas plantas de soja a patamares inferiores a 57\%, aos $40 \mathrm{DAE}$ (Tabela 2 e Figura 1). A baixa umidade do solo pode aumentar a sorção do picloram aos coloides orgânicos e minerais do solo, deixando o herbicida parcialmente inativado. Por outro lado, a manutenção da umidade do solo pode favorecer a permanência do picloram na solução do solo por maior período e, com isso, contribuir para a absorção do mesmo pelo sistema radicular das plantas de capim-tanzânia (fitoextração), concordando com BELO et al. (2007) em estudo com tebuthiuron e trifloxysulfuron sodium, em diferentes doses e teores de água no solo fitorremediado por Canavalia ensiformes e Stilozobium aterrimum.

Outra possibilidade para explicar o incremento da fitorremediação com o aumento da reposição de água no solo seria o fato de o maior teor de água no solo favorecer a atividade microbiana, consequentemente, aumentando a rizodegradação do picloram. A presença do picloram no solo reduziu a altura das plantas de soja, mesmo com a tentativa prévia de remediação do solo contaminado, utilizando-se de plantas de capim-tanzânia (Tabela 3 e Figura 2).

TABELA 3. Altura de plantas de soja semeadas após o cultivo prévio de Panicum maximum (cultivar Tanzânia), sob diferentes lâminas de água no solo contaminado previamente com o herbicida picloram. Height of soybean plants after Panicum maximum cultivation (Tanzania grass) under different water layers in soil previously contaminated with picloram herbicide.

\begin{tabular}{|c|c|c|c|c|}
\hline \multirow{3}{*}{$\begin{array}{l}\text { Doses de picloram } \\
\qquad\left(\mathrm{g} \mathrm{ha}^{-1}\right)\end{array}$} & \multicolumn{4}{|c|}{ Reposição Diária da Lâmina de Água Evaporada (\%) } \\
\hline & 80 & 90 & 100 & 110 \\
\hline & \multicolumn{4}{|c|}{ Altura de Plantas de Soja $(\mathrm{cm})$ aos $15 \mathrm{DAE}^{*}$} \\
\hline 0 & $14,83 \mathrm{a}$ & $14,60 \mathrm{a}$ & $13,90 \mathrm{a}$ & $13,53 \mathrm{a}$ \\
\hline 80 & $9,65 \mathrm{~b}$ & $8,18 \mathrm{~b}$ & $8,50 \mathrm{~b}$ & $9,98 \mathrm{ab}$ \\
\hline 160 & $6,63 \mathrm{~b}$ & $6,10 \mathrm{~b}$ & $6,88 \mathrm{~b}$ & $6,95 \mathrm{~b}$ \\
\hline
\end{tabular}

Médias não seguidas de mesma letra na vertical diferem pelo teste de Tukey, a 5\% de probabilidade. *DAE = dias após a emergência. 


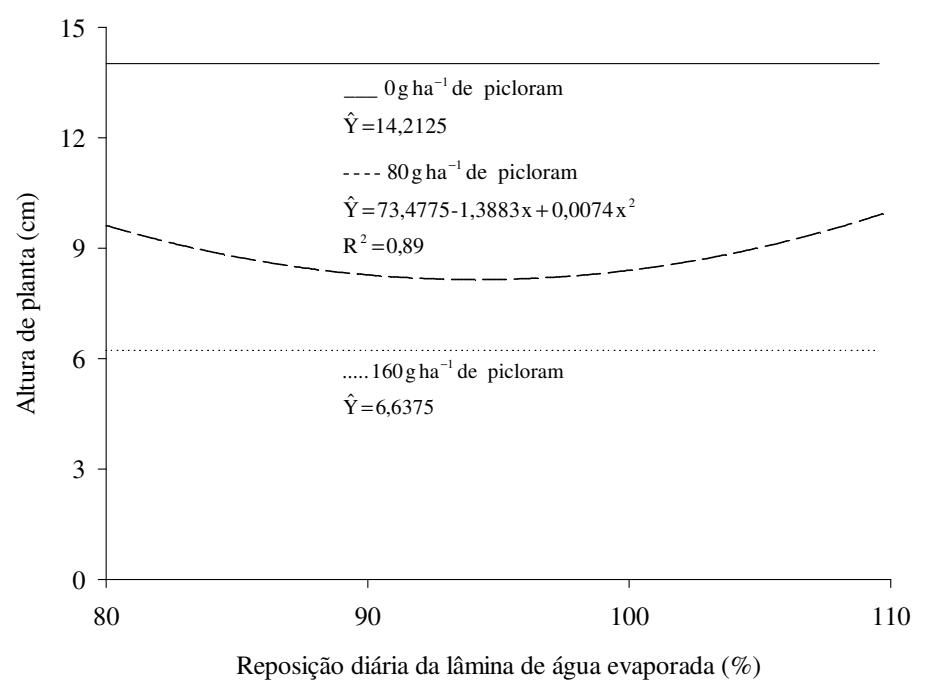

FIGURA 2. Altura de plantas de soja aos 15 dias após a emergência, semeadas após o cultivo prévio de Panicum maximum (cultivar Tanzânia), sob diferentes lâminas de água no solo contaminado previamente com o herbicida picloram. Height of soybean plants 15 days after emergence, planted after Panicum maximum cultivation (Tanzania grass) under different water layers in soil previously contaminated with picloram herbicide.

Não se verificaram efeitos significativos entre as doses do picloram de 80 e $160 \mathrm{~g} \mathrm{ha}^{-1}$ em relação à altura das plantas de soja, em todos os níveis de reposição da água evaporada do solo (Tabela 3). O pequeno ou o alto nível de reposição da água evaporada nos solos resultou em maior eficiência na fitorremediação (Figura 2); todavia, apenas quando o nível de contaminação foi de $80 \mathrm{~g} \mathrm{ha}^{-1}$ em combinação com o maior nível de reposição do solo, é que se obteve redução aceitável no crescimento das plantas de soja, não se verificando diferença estatística em relação ao tratamento sem contaminação prévia (Tabela 3). De acordo com CHANG (1969), as técnicas envolvendo bioensaios são eficientes e podem ser utilizadas na estimativa dos níveis de picloram em solos. MERKLE et al. (1967) empregaram plantas de feijão (Phaseolus vulgaris) para sinalizar a presença de picloram em solo.

A técnica de fitorremediação avaliada, empregando-se plantas de capim-tanzânia, não foi eficiente em garantir pleno acúmulo de massa verde e seca pelas plantas de soja, quando cultivadas em solo que recebeu as duas doses do herbicida picloram (80 e $\left.160 \mathrm{~g} \mathrm{ha}^{-1}\right)$, independentemente da reposição feita da água evaporada do solo (Tabela 4 e Figura 3).

BOVEY \& SCIFRES (1971) reportam que concentrações de picloram de $100 \mathrm{mg} \mathrm{m}^{-3} \mathrm{em}$ solos podem causar significativa redução no crescimento de plantas de girassol e Vigna sinensis. Nos níveis de reposição da água evaporada de 80;100 e 110\% para massa verde, e em todos os níveis para massa seca, é que se detectou maior redução na massa seca da parte aérea das plantas de soja quando cultivadas em solo com aplicação inicial de $160 \mathrm{~g} \mathrm{ha}^{-1}$ do herbicida em relação à contaminação de $80 \mathrm{~g} \mathrm{ha}^{-1}$ (Tabela 4). Mais uma vez, verificou-se que a remediação do solo contaminado com picloram por plantas de capim-tanzânia só foi significativa quando a contaminação do picloram foi de $80 \mathrm{~g} \mathrm{ha}^{-1}$ e a reposição diária de água no solo era a mais baixa $(80 \%)$ ou a mais alta $(110 \%)$ (Tabela 4 e Figura 3$).$ 
TABELA 4. Massa verde e massa seca da parte aérea de plantas de soja semeadas após o cultivo prévio de Panicum maximum (cultivar Tanzânia), sob diferentes lâminas de água no solo contaminado previamente com o herbicida picloram. Green mass and dry mass of the aerial part of soybean plants cultivated after Panicum maximum (Tanzania grass) cultivation, under different water layers in soil previously contaminated with picloram herbicide.
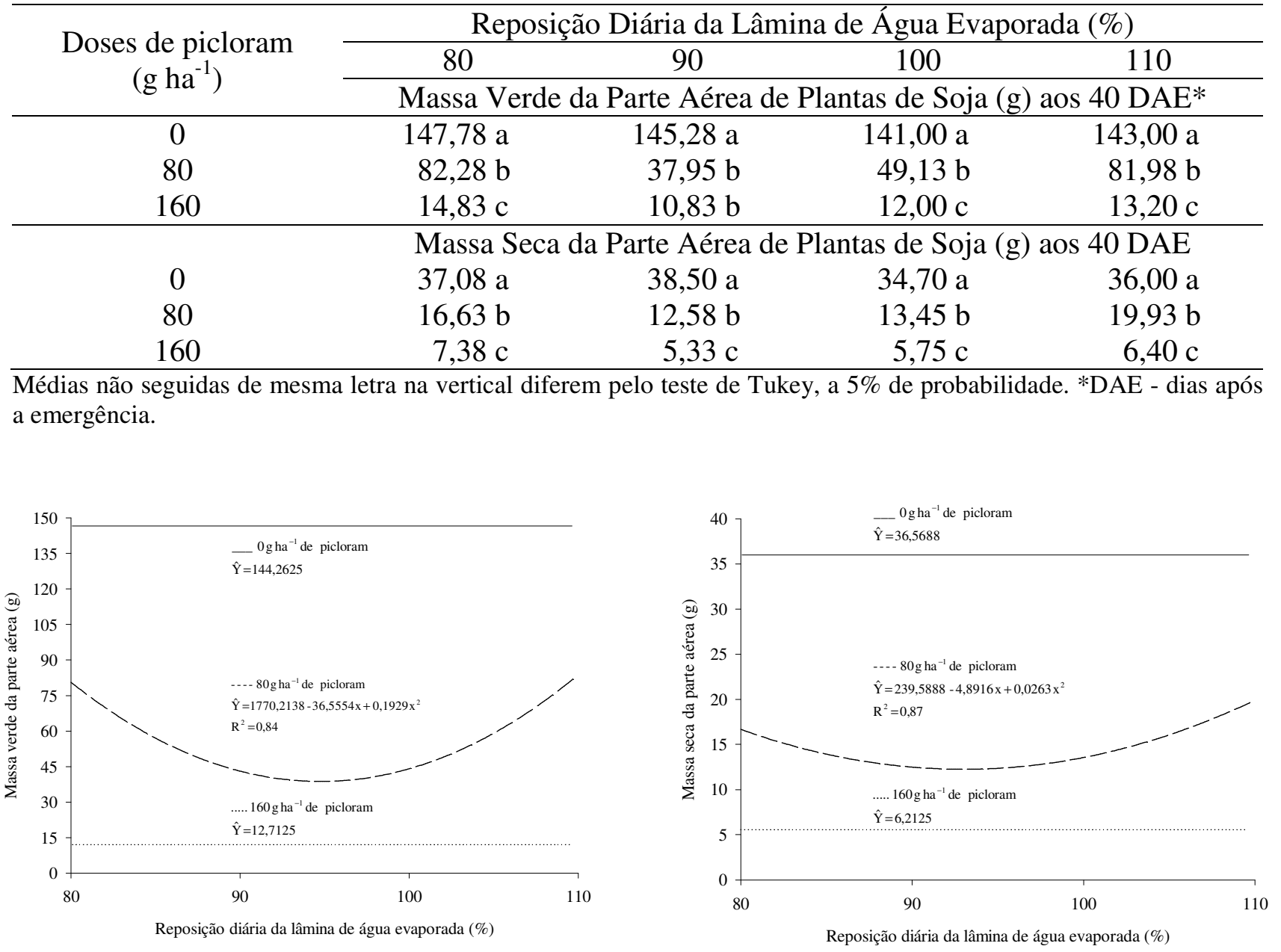

FIGURA 3. Massa verde e massa seca da parte aérea de plantas de soja semeadas após o cultivo prévio de Panicum maximum (cultivar Tanzânia), sob diferentes lâminas de água no solo contaminado previamente com o herbicida picloram. Green mass and dry mass of the aerial part of soybean plants cultivated after Panicum maximum (Tanzania grass), under different water layers in soil previously contaminated with picloram herbicide.

Segundo BELO et al. (2007), de maneira geral, a variação da umidade de 28,7 a 35,8\% não interfere no processo de remediação, observando-se efeitos letais em plantas de soja até 60 dias após a semeadura, quando se utilizaram $C$. ensiformis $e$ S. aterrimum em solo contaminado pelo tebuthiuron.

\section{CONCLUSÕES}

Constatou-se que os valores extremos de umidade avaliados, 80 e $110 \%$ da reposição diária da lâmina de água evaporada, favoreceram a remediação de solos contaminados com o herbicida picloram, utilizando-se, para esse processo, de plantas de capim-tanzânia.

A otimização da fitorremediação não é significativa quando se avaliou o resíduo correspondente a $160 \mathrm{~g} \mathrm{ha}^{-1}$ do herbicida. 


\section{REFERÊNCIAS}

ACCIOLY, A.M.A.; SIQUEIRA, J.O. Contaminação química e biorremediação do solo. In: NOVAIS, R.F.; ALVAREZ V.; V.H.; SCHAEFER, C.E.G.R. (Ed.). Tópicos em ciência do solo. Viçosa: Sociedade Brasileira de Ciência do Solo, 2000. v.1, p.299-352.

ANDERSON, T.A.; COATS, J.R. Screening rhizosphere soil samples for the ability to mineralize elevated concentrations of atrazine and metolachlor. Journal of Environmental Science and Health, v.30, n.4, p.473-484, 1995.

ANDERSON, T.A.; KRUGER, E.L.; COATS, J.R. Enhanced degradation of a mixture of three herbicides in the rhizosphere of a herbicide-tolerant plant. Chemosphere, Kidlingtom, v.28, n.8, p.1.551-1.557, 1994.

BELO, A.F.; SANTOS, E.A.; SANTOS, J.B.; FERREIRA, L.R.; SILVA, A.A.; CECON, P.R.; SILVA, L.L. Efeito da umidade do solo sobre a capacidade de Canavalia ensiformis e Stizolobium aterrimum em remediar solos contaminados com herbicidas. Planta Daninha, Viçosa-MG, v.25, n.2, p.239-249, 2007.

BOVEY, R.W.; SCIFRES, S.J. Residual characteristics of picloram in grassland ecosystems. Texas Agricultural Experiment Station, Bulletin,1.111, 1971. 24 p.

BOYLE, J.J.; SCHANN, J.R. The influence of planting and soil characteristis on mineralization of 2,4,5-T in rhizosphere soil. Journal Environmental Quality, Madison, v.27, n.3, p.704-709, 1998.

CHANG, H.H. Extraction and colorimetric of picloram in soil. Journal of Agricultural and Food Chemistry, Washington, v.17, n.6, p.1.174-1.177, 1969.

CONSTANTIN, J.; OLIVEIRA JÚNIOR, R.S. de; BRANDÃO, J.U.T.; CALLEGARI, O.; PAGLIARI, P.H.; ARANTES, J.G.Z de. Efeito de subdoses de 2,4-D na produtividade de fumo e suscetibilidade da cultura em função de seu estádio de desenvolvimento. Engenharia Agrícola, Jaboticabal, v.27, n. esp., p.30-34, 2007a.

CONSTANTIN, J.; OLIVEIRA JÚNIOR, R.S. de; FAGLIARI, J.R.; PAGLIARI, P.H.; ARANTES, J.G.Z de; CAVALIERI, S.D.; FRAMESQUI, V.P.; GONÇALVES, D.A. Efeito de subdoses de 2,4D na produtividade do algodão e suscetibilidade da cultura em função de seu estádio de desenvolvimento. Engenharia Agrícola, Jaboticabal, v.27, n. esp, p.24-29, 2007 b.

CUNNINGHAM, S.D.; ANDERSON, T.A.; SCHWAB, A.P. Phytoremediation of soils contaminated with organic pollutants. Advances in Agronomy, San Diego, v.56, n.1, p.55-114, 1996.

D'ANTONINO, L.; SILVA, A.A.; FERREIRA, L.R.; CECON, P.R.; QUIRINO, A.L.S.; FREITAS, L.H.L. Efeitos de culturas na persistência de herbicidas auxínicos no solo. Planta Daninha, Campinas, v.27, n.2, p.371-378, 2009.

EMBRAPA. EMPRESA BRASILEIRA DE PESQUISA AGROPECUÁRIA. Centro Nacional de Pesquisa de Solos. Manual de métodos de análise de solo. 2.ed. Rio de Janeiro, 1997. 212 p.

MACEK, T.; MACKOVÁ, M.; KÁŠ, J. Exploitation of plantas for the removal of organics in environmental remediation. Biotechnology Advances, Tarrytown, v.18, n.1, p.23-34, 2000.

MERKLE, M.G.; BOVEY, R.W.; DAVIS, F.S. Factors affecting the persistence of picloram in soil. Agronomy Journal, Madison, v.59, n.5, p.413-415, 1967.

PERKOVICH, B. S.; ANDERSON, T. A.; KRUGER, E. L.; COATS, J. R. Enhanced mineralization of $\left[{ }^{14} \mathrm{C}\right]$ atrazine in Kochia scoparia rhizosferic soil from a pesticide-contaminated site. Pesticide Science, Chichester, v.46, n.4, p.391-396, 1996.

PROCÓPIO, S. O.; SANTOS, J.B.; PIRES, F.R.; SILVA, A. A.; SANTOS, E.A.; CARGNELUTTI FILHO, A. Development of bean plants in soil contaminated with trifloxysulfuron-sodium after 
Stizolobium terrimum and Canavvalia ensiformis cultivation. Planta Daninha, Viçosa-MG, v.25, n.1, p.87-96, 2007.

RICE, P.J.; ANDERSON, T.A.; COATS, J.R. Phytoremediation of herbicide-contaminated surface water with aquatic plants. In: KRUGER, E.L.; ANDERSON, T.A. (Ed.) Phytoremediation of soil and water contaminants. Washington, DC: American Chemical Society, 1997. p.133-151.

RODRIGUES, B.N.; ALMEIDA, F.S. Guia de herbicidas. 5.ed. Londrina: Grafmarke, 2005. 591 p.

SCRAMIN, S.; SKORUPA, L.A.; MELO, I.S. Utilização de plantas na remediação de solos contaminados por herbicidas - levantamento da flora existente em áreas de cultivo de cana-de-açúcar. In: MELO, I.S.; SILVA, C.M.M.S.; SCRAMIN, S.; SPESSOTO, A. Biodegradação. Jaguariúna: EMBRAPA Meio Ambiente, 2001. p.369-371.

WAX, L.M.; KNUTH, L.A.; SLIFE, F.W. Response of soybeans to 2,4-D, dicamba and picloram. Weed Science, East Perth, v.17, n.3, p.388-393, 1969.

WILSON, P.C.; WHITWELL, T.; KLAINE, S.J. Phytotoxicity, uptake, and distribution of ${ }^{14} \mathrm{C}-$ simazine in Canna hybrida 'Yellow King Hunbert'. Environmental Toxicology and Chemistry, Pensacola, v.18, n.7, p. 1.462-1.468, 1999.

WILSON, P.C.; WHITWELL, T.; KLAINE, S.J. Phytotoxicity, uptake, and distribution of ${ }^{14} \mathrm{C}-$ simazine in Acorus gramenius and Pontederia cordata. Weed Science, v.48, n.6, p.701-709, 2000. 